\title{
REGIME DE ACUMULAÇÃO FLEXÍVEL E SAÚDE DO TRABALHADOR
}

\author{
Maria Beatriz Costa Abramides \\ Maria do Socorro Reis Cabral
}

\begin{abstract}
Resumo: Analisar a saúde do trabalhador exige, na contemporaneidade, a compreensão do impacto do regime de acumulação flexível como resposta do capital e do capitalismo, seus rebatimentos nas relações de trabalho, bem como a compreensão das respostas articuladas pelo Estado, valendo-se de reformas neoliberais. Elas têm transferido as ações de saúde para a circunscrição do mercado, o que significa, em última instância, inserir o Estado no campo de ação da concorrência, do capital. Com base nesse enfoque é que se estruturou a abordagem do tema.

Palavras-chave: saúde do trabalhador; flexibilidade; processo de trabalho.
\end{abstract}

Abstract: Analyzing employee health care requires, in these times, an understanding of the impact of the flexible accumulation regime as a response to capital and capitalism and how both are reflected in labor relations. Also required is an understanding of the State's neoliberal approach to reform, which has transferred health care issues to the domain of the market, ultimately positioning the State in a competitive role against capital. Key words: employee health care; flexibility; labor process.

$\mathrm{A}$ nalisar o impacto do regime de acumulação flexivel $^{1}$ na saúde do trabalhador pressupõe compreender a crise estrutural do capital e do capitalismo no plano internacional em sua crise mais profunda e prolongada, iniciada a partir de 1973, no epicentro do capitalismo. Essa crise estrutural cinge, em sua gênese, a própria crise mundial do petróleo e a queda tendencial da taxa de lucro. Em réplica a esses fatos, o capital busca alternativas para retomar seus níveis de acumulação, que se expressam em novas formas de gestão e controle do trabalho, e obtêm a ampliação da exploração da força de trabalho, pela mais-valia relativa (inovação tecnológica) e pela mais-valia absoluta (ampliação do ritmo de trabalho).

Essas mudanças no processo produtivo têm na acumulação flexível sua referência central, cujo esteio advém da "flexibilidade dos processos de trabalho, dos mercados, dos produtos e padrões de consumo" (Harvey, 1995:140). Essas mudanças repercutem na reprodução social - esfera do Estado - que, com a implantação do neoliberalismo, passa a reger-se pela soberania do mercado. O processo de trabalho sofre profundas modificações, na década de 80 , nos países de capitalismo avança- do, com desdobramentos e inflexões diferenciadas, a partir da década de 90, nos países industrializados do chamado Terceiro Mundo.

As modificações ocorridas pela diferenciação dos processos de trabalho na produção: fordismo, taylorismo e toyotismo, ou acumulação flexível, pressupõem, na ordem do capital, formas diferenciadas de exploração, culminando na acumulação flexível, cujas repercussões profundas afetam a "objetividade e subjetividade da classe-que-vivedo-trabalho, e, portanto, a sua forma de ser" (Antunes, 1995:15).

O fordismo, como maneira de organização do trabalho, surge em 1914, quando Henry Ford introduz a jornada de 8 horas a cinco dólares de recompensa para o trabalho em linha de montagem, e se espraia pelo setor produtivo. Essa forma de organização desenvolve-se e consolida-se nos países capitalistas ocidentais em meados da década de 70. Apresentando momentos de diferenciação em seu desenvolvimento, pode-se dizer que atinge a maturidade no período imediato ao pós-guerra, persistindo até 1973. "O fordismo pode ser compreendido, fundamentalmente, como a forma pela qual a indústria e o processo de trabalho consolidaram-se ao longo 
deste século [...], e cujos elementos constitutivos básicos eram dados pela produção em massa, através da linha de montagem e de produtos mais homogêneos; através do controle do tempo e movimentos, pelo cronômetro taylorista e produção em série fordista" (Antunes, 1995:17).

$\mathrm{O}$ fordismo e o taylorismo, ${ }^{2}$ que predominaram em grande parte da indústria capitalista, apresentam ainda como característica "a separação entre a elaboração e a execução no processo de trabalho: fragmentação das funções, trabalho parcelar pela existência de unidades fabris concentradas e verticalizadas e pela construção e consolidação do operário-massa, do trabalhador fabril" (Antunes, 1995:17).

O fordismo apresenta uma separação entre gerência, concepção, controle e execução ante um novo tipo de reprodução da força de trabalho, no reconhecimento explícito de que produção em massa significava consumo em massa (Harvey, 1995). Essa forma produtiva, presente no tecido social, foi construindo uma cultura e um modo de vida, firmando "um esforço coletivo para criar, com velocidade sem precedentes e com uma consciência sem igual na história, um novo tipo de homem, um novo tipo de trabalhador [...] um modo específico de viver, pensar e sentir a vida" ajustado à nova forma de trabalho e ao novo processo produtivo (Gramsci apud Harvey, 1995:121). Estruturou-se, enfim, o novo sistema de reprodução da força do trabalho, um novo sistema de controle, de gerência, uma nova psicologia, um novo tipo de sociedade democrática, racionalista e capitalista. $\mathrm{O}$ consumo em massa, necessário aos padrões de acumulação fordista "subsumiu o tempo e o lazer" do trabalhador a certo tipo de controle necessário às expectativas e à racionalidade da produção.

Nesse período, o capitalismo atingiu altas taxas de expansão mundial. Um momento histórico de ondas largas, expansivas do capitalismo, e foi considerado "a era de ouro" (E. Hobsbawm). A produção fordista e a reprodução keynesiana tornaram-se fortes aliadas no processo capitalista de desenvolvimento do pós-guerra.

A regulação e a intervenção estatal keynesiana, consubstanciada no Estado de bem-estar social - Welfare State -, ocorre nos países centrais do capitalismo, operando uma gestão social do sistema e concretizando "um Estado com forte iniciativa no campo de políticas sociais redistributivas e com pronunciada intervenção por serviços e equipamentos sociais, fiador de controles tributários sobre o capital e articulador institucional de parce- rias entre capital e trabalho, sobre a base do jogo político democrático" (Netto, 1994:98).

Durante esse processo de expansão do capitalismo, o Estado desenvolve políticas sociais e de emprego afinadas com as exigências de produtividade e de lucratividade das empresas sob controle do grande capital. Essa intervenção regulacionista, longe de ser universal, é voltada unilateralmente para a força de trabalho economicamente ativa e inserida no sistema produtivo.

O keynesianismo, ao desenvolver políticas sociais e de emprego, incorpora um Estado de Regulação, de reivindicações dos trabalhadores que passam a ceder ao ideário do pacto social fordista-keynesiano. Esse acordo configura a derrota do movimento sindical operário, que consolidou o terreno político para a hegemonia do pacto especificado, e consubstanciou um sindicalismo nos marcos da institucionalidade, com garantia de um terreno seguro para o movimento do capital.

Nos países periféricos, incluindo-se aí a América Latina, e entre eles o Brasil, o Welfare State não se consolidou, já que suas economias encontravam-se subordinadas ao capitalismo monopolista, ainda que tivessem um Estado com algum sistema de proteção social. É importante frisar que, no Brasil, as políticas sociais, do período Vargas à Constituição de 1988, segundo Vieira, têm refletido o comportamento de uma classe dirigente que oscila entre a inércia e a modernização, imposta de fora, orientado pelo grande capital.

As transformações econômicas e sociais ocorridas nos anos 70, associadas ao acirramento da concorrência mundial no mundo capitalista e ao emprego de novas tecnologias, configurando o que se convencionou chamar de Terceira Revolução Industrial, contribuíram para afirmar e moldar um novo processo de acumulação de tipo flexível.

A acumulação flexível caracteriza-se pelo surgimento de setores de produção inteiramente novos, novas maneiras de fornecimento de serviços financeiros, novos mercados e, sobretudo, taxas altamente intensificadas de inovação comercial, tecnológica e organizacional. Envolve, também, rápidas mudanças dos padrões de desenvolvimento desigual, tanto entre setores como entre regiões geográficas, criando, por exemplo, um vasto movimento no emprego do chamado "setor de serviços", bem como conjuntos industriais completamente novos em regiões até então subdesenvolvidas" (Harvey, 1995:140).

A acumulação flexível, com o toyotismo, torna-se para o capital tanto uma forma de maior exploração quanto de maior controle sobre a força de trabalho. A reestruturação 
produtiva está baseada em aumento de produtividade, eficiência, qualidade, novas formas de tecnologia e de gestão, efetivando-se por intermédio das inovações tecnológicas. Desse processo de trabalho advém basicamente a precarização e a desestruturação das relações clássicas de produção, de gerenciamento e de envolvimento da força de trabalho. Viabilizam-se os Círculos de Controle de Qualidade (CCQs) - e o Comprometimento com a Qualidade Total (TQC), exigindo a participação dentro da ordem e do universo da empresa (Antunes, 1995:16). As decorrências desse processo favoreceram o processo de flexibilização do trabalho que conduziu à desregulamentação de direitos sociais e trabalhistas: reduziu o quantitativo do operariado fabril; incrementou a terceirização e a subproletarização; estimulou o trabalho precário e parcial e ampliou o desemprego estrutural, entre outros danos trabalhistas. Pode-se apontar, ainda, o surgimento do operário polivalente, o aumento da produtividade, a redução do operariado fabril, o atrelamento da mercadoria à demanda determinada, ou seja, a manutenção do estoque mínimo, conforme a lógica do just in time, que objetiva "o melhor aproveitamento possível do tempo de produção (incluindo-se também o transporte, o controle de qualidade e o estoque)" (Antunes, 1995:26), e o sistema kanban, que utiliza placas ou senhas para a reposição de preços e de mercadorias, mantém os estoques no mínimo, para repô-los de acordo com a demanda, constituindo ambos a substância do modelo japonês.

O mercado de trabalho passa por mudanças radicais em razão do processo de acumulação flexível, com flutuações constantes, aumento da competição, redução do poder aquisitivo do trabalhador e enfraquecimento do poder sindical, que começa a atuar na defensiva em razão da grande quantidade de mão-de-obra excedente (desempregados ou subempregados, ou precarizados vinculados à economia informal), o que dissocia ainda mais os interesses da classe trabalhadora.

O processo de trabalho em curso no toyotismo apresenta uma base de sustentação ideológica que atinge não somente a objetividade - base material da classe operária -, mas também sua subjetividade - sua consciência de classe, sua organização e seus valores. Os CCQs e TQCs são instrumentos diretos de propagação ideológica e de cooptação dos trabalhadores. Estabelece o "envolvimento cooptado", em que a subsunção do trabalho ao capital é superior à existente nos processos de trabalho anteriores, em que na nova lógica organizacional o trabalhador passa a ser o controlador de si mesmo. Nos CCQs a empresa é concebida como o prolongamento da casa, e o debate estabelece-se a fim de traçar metas e objetivos para que o trabalhador possa se destacar na empresa, como forma de amenizar os processos de luta da classe trabalhadora em seu campo de autonomia e independência de classe. Fica óbvio o lema da Toyota: "Proteger a nossa empresa para defender a vida", o que expressa, de modo claro, a perspectiva ideopolítica adotada nesse processo de trabalho desenvolvido pelo capital.

O "sindicato-casa" é incentivado, na condição de organização cooptadora, para ser o interlocutor dos trabalhadores que são denominados pela empresa de "colaboradores", e o que se confirma em todo o processo produtivo é a ampliação da exploração da classe trabalhadora.

A desconcentração do espaço físico e a concentração de capital constituem o desafio mais intenso que o capital cria para a classe trabalhadora. A motivação exploradora da atual introdução de novas tecnologias evidencia-se na mobilidade do capital para regiões que oferecem o barateamento da força de trabalho, possibilitando, por um lado, uma maior lucratividade para a mercadoria, sob controle dos oligopólios, na internacionalização da economia e do capital, e, por outro, um aumento na exploração da classe trabalhadora.

Uma outra decorrência que se evidencia, no caso brasileiro, é o processo de desindustrialização que vem sucedendo em grandes centros industriais como São Paulo e o ABC Paulista, com a migração das empresas para o interior e para outros Estados que oferecem redução nos custos, liberação de impostos e força-de-trabalho mais barata e menos organizada.

Concretamente, porém, não se pode afirmar que tudo seja toyotismo, pois o processo de desfordização encontra-se em curso. Portanto, os processos de trabalho expressam-se de forma mesclada e diferenciada em diversos países, acarretando o desemprego tecnológico, associado ao forte desemprego estrutural inerente à profunda crise do capital.

O receituário produtivo apresenta ainda como características a complexificação e a heterogeneidade da classe trabalhadora; o trabalho operado em equipe, apresentando multiplicidade e flexibilidade de funções; e a ampliação e diversificação das formas de exploração do trabalho humano.

A competitividade e a concorrência intercapitalista produz a destruição ou a precarização, sem precedentes na era moderna, da força humana que trabalha e a degradação crescente que destrói o meio ambiente, na relação 
metabólica do homem com a natureza no processo de produção de mercadorias e valorização do capital (Antunes, 1998).

\section{PROGRAMÁTICA NEOLIBERAL EM CONSONÂNCIA COM A ACUMULAÇÃO FLEXÍVEL}

O processo de reestruturação do capitalismo estabelece dois tipos de ajuste estrutural distintos, mas inerentes ao movimento do capital: o primeiro ocorre na esfera da produção, mais conhecida como reestruturação produtiva (base material da sociedade), e o segundo na esfera política do Estado referenciado ao neoliberalismo.

O neoliberalismo surge após a Segunda Guerra Mundial, na Europa e na América do Norte, como uma reação contra o Estado de Regulação de bem-estar Social, sustentado pela social-democracia, no modelo keynesiano. $\mathrm{O}$ texto de origem do neoliberalismo, escrito por Hayek, em 1944, intitulava-se $O$ caminho da servidão. De acordo com a ideologia e a teoria proposta nesse ideário neoliberal, era necessário combater as raízes da crise que se originava no poder dos sindicatos e do movimento operário, que pressionavam por melhores salários, condições de vida e trabalho e ampliavam os gastos sociais, assumidos pelo Estado. Desse modo, seu propósito era o de "combater o keynesianismo e o solidarismo reinantes e preparar as bases de um outro tipo de capitalismo, duro e livre de regras para o futuro" (Anderson, 1995:10). Nesse momento, o ataque era dirigido diretamente ao Partido Trabalhista inglês. As idéias neoliberais passam, porém, ao plano da ação programática em 1973, quando o mundo capitalista enfrenta uma crise estrutural, com longa e profunda recessão, combinando, pela primeira vez, baixas taxas de crescimento com altas taxas de inflação (Anderson, 1995). Margareth Thatcher, em 1979, na Inglaterra e Ronald Reagan, em 1980, nos Estados Unidos, iniciam a implantação do neoliberalismo, possibilitando ao grande capital arquitetar um plano internacional de expansão. Na América Latina, sua execução mais severa inicia-se em 1989, para dar cumprimento ao Consenso de Washington ${ }^{3}$ - agora, aprimorado com o Dissenso de Washington, 2000 que responde aos ditames do FMI e do Banco Mundial e concretiza-se na abertura de novos espaços de exploração do capital privado e na disseminação da presença do Estado na economia.

A programática neoliberal preconiza a concepção de que "o mercado é entronizado como instância societal mediadora por excelência no plano econômico e no plano político, sacralizando o Estado mínimo" (Netto, 1994:75). Essa programática, consubstanciada, portanto, no Estado mínimo e mercado máximo, é a expressão da reestruturação produtiva, delineada no processo que vincula economias nacionais e internacionais em um novo momento da mercadoria e da divisão social do trabalho, como se refere Mota.

O projeto neoliberal oriundo da estratégia internacional do capital estabelece uma política econômica monetarista com ampla privatização de empresas estatais, em que o "Estado mínimo" e o "máximo de mercado" são elementos constitutivos do grande capital dos oligopólios.

O neoliberalismo rege-se pela soberania do mercado. Na América Latina sua execução dar-se-á com base em: disciplina fiscal, estabilidade monetária, redução de gastos públicos, reforma tributária, liberalização financeira e comercial, alteração das taxas de câmbio, investimento direto estrangeiro, privatizações e desregulamentação.

As políticas neoliberais implantadas por Reagan e Thatcher têm "nos social-democratas os grandes executores dessas políticas: Mitterrand, na França; Gonzáles, na Espanha; Soares, em Portugal; Craxi, na Itália; Papandroeou, na Grécia" (Anderson, 1995). As economias do Leste europeu são atingidas pelo neoliberalismo, após sua derrocada, em 1989.

A primeira experiência neoliberal sistemática do mundo ocorreu no Chile, em 1973, e serviu como laboratório internacional. Pinochet implementou o ideário neoliberal com dura repressão ao movimento operário e socialista do país, instalando "uma das mais cruéis ditaduras militares do pós-guerra" (Anderson, 1995:19). A Bolívia também foi pioneira na América Latina, pois tal programa iniciou-se no ano de 1983. Nos demais países latino-americanos, o fim dos anos 80 significou a expansão do neoliberalismo: no México, consolida-se em 1988; na Argentina, com Menen, em 1989; na Venezuela, com Peres, em 1988; e no Peru, com Fugimori, em 1990.

A ofensiva neoliberal no Brasil inicia-se no final do governo Sarney e perpassa os governos Collor e Itamar, aprofundando-se e consolidando-se com FHC (1994/ 2002). Sua implantação vem imprimindo uma política monetarista com ajustes econômicos efetivados com base na oferta monetária, na privatização de estatais e de serviços públicos rentáveis, no corte nos gastos sociais, até com demissão de trabalhadores em serviço público, na transferência de renda e de patrimônio público para o setor do capital privado, na quebra de monopólios com a 
entrada do capital estrangeiro, na privatização de setores estratégicos associada à internacionalização (petróleo, telecomunicações, siderurgia, mineração), na sobrevalorização da taxa cambial, na mercantilização de políticas sociais, acompanhada da refilantropização na área da assistência, nas políticas sociais compensatórias, em substituição a políticas sociais de caráter universal; na privação de direitos sociais (educação, saúde, previdência, assistência) e na desregulamentação de direitos sociais e trabalhistas. O neoliberalismo consubstancia o Estado mínimo para os trabalhadores e o Estado ampliado para o capital, em que os interesses privados sobrepõem-se aos interesses públicos, de caráter universal.

Nessa perspectiva, a Reforma do Estado 4 prevê a existência de um núcleo estratégico em que se definam políticas; um setor de atividades essenciais, compreendendo as áreas de auditoria, fisco, segurança, arrecadação de impostos e tributos e de advocacia, etc. Nas chamadas áreas sociais o Estado concorre com o mercado, com repercussões na política de seguridade, saúde e previdência, e nas áreas de educação e cultura. Um quarto setor compreende as atividades exclusivamente de mercado, com amplo programa de privatização.

A política de seguridade - saúde, previdência e assistência -, com a Constituição de 1988, são definidas como de caráter universal e equitativas, mas, na óptica neoliberal, são redefinidas e orientadas por uma política que associa publicização e privatização.

\section{O PROCESSO SAÚDE E DOENÇA DOS TRABALHADORES E AS RESPOSTAS ARTICULADAS DO ESTADO}

A VIII Conferência Nacional de Saúde, realizada em Brasília-DF em 1986, expressou uma concepção ampla de saúde, entendendo-a como "a satisfação das necessidades básicas de acesso a uma alimentação regular e nutritiva, moradia adequada, transporte seguro, serviços de saúde e educação eficientes, para além da simples ausência de doenças, a falta de uma renda mínima que assegure esses direitos, constitui-se para uma ampla camada de trabalhadores, em efetiva deterioração de suas condições de vida e reprodução da força de trabalho" (Mattos et al., 1995:48).

Compreender a saúde nessa dimensão significa entendê-la nas diversas formações sociais e na divisão social e técnica do trabalho. No capitalismo as condições objetivas e subjetivas da classe trabalhadora e sua própria condição de classe são afetadas pelo caráter destrutivo do capital, em sua estrutura orgânica metabólica de relação dos homens entre si e com a natureza, em que a propriedade privada dos meios de produção, a superexploração da força de trabalho, e o Estado a serviço da ordem burguesa determinam um viver e morrer. A força de trabalho, considerada mercadoria básica no processo de produção capitalista, é requerida pelo mercado, mas lhe é exigido ter a saúde necessária para executar um processo de trabalho: "Para o capital, a saúde - entenda-se a saúde suficiente - é um simples e relativizado componente da mercadoria força de trabalho" (Ribeiro, 1997:102). Portanto, saúde e capacidade técnica são elementos indissociáveis da capacidade de trabalho. A força de trabalho é para ser consumida e substituída na medida de seu desgaste, como qualquer outro componente do processo de produção. O trabalhador tem, por sua vez, consciência de sua capacidade técnica e sabe que, para exercitá-la, precisa ter saúde. A relação indissociável entre saúde e capacidade técnica, e o processo histórico de lutas da classe trabalhadora pela redução da jornada de trabalho e por melhores condições de vida, possibilita ampliar postos de trabalho bem como proteger esses dois componentes da capacidade produtiva.

A intensidade e o ritmo acelerado no trabalho e o número excessivo de horas na jornada são decisivos na precarização da saúde do trabalhador, podendo eliminálo, precocemente, do mercado. Nas condições de trabalho estão incluídas as atividades corporais e mentais dos trabalhadores, bem como os elementos materiais, físicoquímicos, ambientais, temporais e também as relações de trabalho.

O capital, historicamente, incorpora o trabalho da mulher, o infantil e o da juventude desde o primeiro ciclo da Revolução Industrial, na Inglaterra, como forma de ampliar sua exploração, dilatando a margem de mais-valia, o que concorre para o barateamento do preço da força de trabalho: "O valor da força de trabalho era determinado não pelo tempo de trabalho necessário para manter individualmente o trabalhador adulto, mas pelo necessário à sua manutenção e a de sua família. Lançando à máquina todos os membros da família do trabalhador no mercado de trabalho, reparte ela o valor da força de trabalho do homem adulto pela família inteira. Assim, desvaloriza a força de trabalho do adulto" (Marx apud Ribeiro, 1997:104).

O movimento operário brasileiro desde sua origem vem lutando pela garantia de uma jornada de trabalho reduzi- 
da, sem redução de salário, e obteve algumas conquistas que hoje estão ameaçadas pela flexibilização dos direitos trabalhistas, pela prevalência do acordado sobre o legislado.

Outro elemento analítico a ser considerado na compreensão da saúde é a relação da força de trabalho nas diferentes ocupações requeridas pela divisão sociotécnica do trabalho nos diferentes ramos da atividade econômica. Os componentes que caracterizam o exercício de determinada ocupação são históricos e sociais, mutáveis no tempo e no espaço, com conseqüências diferenciadas entre essas doenças, embora, em dado processo produtivo, em certo espaço sociocupacional, possam ocorrer casos imediatos ou próximos de doenças recorrentes e acidentes do trabalho, mas a existência desses fenômenos não pode levar a uma neutralização do risco ou do dano, uma vez que ambos inserem-se em uma temporalidade sóciohistórica e cultural específica.

É possível, ainda, uma terceira dimensão que pode influir na condição de saúde, embora os trabalhadores vivenciem as mesmas circunstâncias de vida e de trabalho, dadas por sua condição de classe, exercendo funções semelhantes, muitas vezes em uma mesma empresa ou ocupação com relações de trabalho semelhantes, e que podem ou não vir a ser afetados em sua condição de saúde individual.

A dimensão social da saúde é "abrangente e corresponde ao ciclo do capitalismo e às condições objetivas onde ele se desenvolve. Ela se expressa nas relações sociais e de produção e tem a ver também com as tecnologias dos processos produtivos e de organização do trabalho incorporados pelas empresas. A causalidade mais ou menos aparente do trabalho com a ocorrência de doenças e acidentes é apenas um modo violento e explícito de evidenciar essa determinação" (Ribeiro, 1997:65).

A Saúde do Trabalhador, diretamente vinculada ao processo de relações sociais de produção, apontou para a necessidade de uma discussão, de um debate e de uma intervenção na área denominada Saúde do Trabalhador na rede pública de serviços de saúde no Brasil a partir da década de 80 , impulsionada pelas lutas e reivindicações do movimento dos trabalhadores. Portanto, a área da Saúde do Trabalhador surge como "uma prática social instituinte, que se propõe a contribuir para a transformação da realidade de saúde dos trabalhadores, e por extensão a da população como um todo, a partir da compreensão dos processos de trabalho particulares, de forma articulada com o consumo de bens e serviços e o conjunto de valores, crenças, idéias e representações sociais próprios de um dado momento da história humana" (Dias, 1995:27).

O objeto da Saúde do Trabalhador pode ser definido como o processo de saúde e doença dos homens em sua relação com o trabalho. Trabalho, no capitalismo, é entendido como a subsunção do trabalhador ao capital no processo produtivo de superexploração do trabalho humano e extração da mais-valia, mas também compreendido como pólo de resistência e luta dos trabalhadores por melhores condições de vida e trabalho, em que a saúde é parte constitutiva desse processo.

No Brasil, desde 1988 a Saúde do Trabalhador configura-se como prática institucionalizada no interior do Sistema Único de Saúde e do ponto de vista da luta sindical. A CUT organiza o Instituto de Saúde no Trabalho para instrumentalizar o processo de luta e negociação dos trabalhadores. A política relativa aos benefícios acidentários foi incorporada como cobertura prestada pela Previdência Social, em 1969, constituindo-se no Seguro-Acidente. Alterações substantivas vêm sendo realizadas no Seguro-Acidente, com a alteração do cálculo, com perdas visíveis para os trabalhadores, além de alterações na sistemática de comunicação do acidente.

É importante ressaltar que o governo FHC, embora já tenha lançado a debate público a proposta de liquidação do Seguro-Acidente, nos marcos da Previdência Pública estatal, substituindo-a pela criação de Mútuas - organização associada constituída pelo patronato e pelos trabalhadores -, acredita-se que a pressão do próprio movimento sindical tem dificultado a efetivação de tal proposta.

\section{IMPACTOS DO REGIME DE ACUMULAÇ̃̃O FLEXÍVEL}

A reestruturação produtiva no Brasil, com a precarização das relações de trabalho, a intensificação de ritmos, a perda de postos de trabalho e a exigência de polivalência (requisições diferenciadas na atividade laborativa) têm ampliado e agravado o quadro de doenças e riscos de acidentes nos espaços socioocupacionais. As inovações tecnológicas, a microeletrônica, a robótica e a automação presente na atual fase de reprodução do capital no plano internacional e nacional ampliam as doenças relativas ao trabalho, como a LER/Dort (lesões por esforço repetitivo e distúrbios osteomoleculares), em setores de produção individual ou de serviços, descortinando um dos frutos mais dramáticos do processo de acumulação flexível e afetando, conseqüentemente, as condições 
de trabalho e de existência desses trabalhadores em seu cotidiano nas diferentes esferas da vida social. Os registros de LER/Dort incidem com maior freqüência em algumas atividades ocupacionais: digitadores, caixas de banco e comércio, telefonistas, empacotadores, trabalhadores de empresas de processamento de dados, entidades comerciais e financeiras, indústria editorial e metalúrgica, entre outros, e, particularmente, na área de telemarketing a LER tem crescido em ritmo acelerado. E nos quadros clínicos da LER/Dort, incluem-se: tenossinovite, tendinite, bursite e mionite, provocando inflamação em várias áreas dos membros superiores. Esse quadro associa-se, de um lado, à incorporação de novas tecnologias, máquinas digitais, computadores e maquinário em geral, com a aceleração do ritmo de trabalho, de modo que possa responder às exigências do processo produtivo; de outro, as atividades repetitivas não qualificadas têm sido também responsáveis por quadros de LER.

A precarização das relações de trabalho com demissões constantes, trabalho por tempo determinado, desemprego, terceirização, quarteirização, perda de direitos sociais e trabalhistas são expressões de um conjunto de efeitos das relações de trabalho sobre a saúde do trabalhador, como estafas, fadigas, ansiedades e insegurança permanente, dores lombares e generalizadas, distúrbios emocionais, dentre outros. Portanto: “os males da saúde ocasionados pela ausência de trabalho não são somente aqueles vinculados à queda do nível de qualidade de vida e, conseqüentemente, da condição geral de saúde, mas, também, aqueles relacionados ao sofrimento mental advindos do sentimento de impotência individual, sensação de carência de sentidos da vida, ausência de normas, distanciamento cultural e isolamento social, que resultam normalmente em respostas psicológicas básicas, como agressão, repressão, fixação (comportamentos rígidos e estereotipados), apatia (Lira e Weinstein apud Mattos et al., 1995:49).

É importante ressaltar que no cenário produtivo brasileiro convivem as novas tecnologias do processo de acumulação flexível e sua forma estruturante de trabalho com processos de trabalho fordista/taylorista clássicos, em que ainda predominam os acidentes de trabalho típicos - amputação, morte e doenças profissionais características de ramos de produção como: silicose, asbestoses, hidragerinos, bezenismo, entre outras.

Os processos de terceirização e quarteirização têm sido responsáveis pela realização de atividades produtivas no interior das residências dos trabalhadores, com expansão do risco para além das fronteiras dos espaços socioocupacionais, atingindo crianças e mulheres. Outro aspecto a considerar é o do aumento da presença feminina em atividades precarizadas, com baixos salários, sem direitos previdenciários e trabalhistas. Para as que estão inseridas, formalmente, no mercado de trabalho, existe a constante ameaça de retirada desses direitos, como a licença-maternidade e a possibilidade de demissão no período de gestação (abandono da Convenção 103 da Organização Internacional do Trabalho).

A importação de mais tecnologia, por sua vez, tem configurado a transferência de tecnologias obsoletas e perigosas, causando danos ao meio ambiente e à saúde da população.

As transformações profundas ocorridas nessa quadra histórica, no ambiente da internacionalização do capital e do capitalismo em sua crise estrutural, com alterações significativas no processo produtivo e na esfera do Estado, vem destruindo conquistas sociais históricas da classe trabalhadora na luta por melhores condições de vida e trabalho. Essa razão destrutiva aliena ainda mais o trabalho humano, apresentando um quadro de miséria e de destruição da própria vida.

A relação saúde-doença é fortemente afetada nesse processo de barbarização da vida social pela investida do grande capital. O desafio posto para a classe trabalhadora é o de retomar seus instrumentos de luta - o partido e o sindicato no âmbito da autonomia e da independência de classe. Estes, na última década, vêm sofrendo uma inflexão significativa com um giro do movimento na direção social-democrata e abandono gradativo das lutas sociais em detrimento de acordo na esfera da institucionalidade. $\mathrm{O}$ grande desafio para a classe trabalhadora é a retomada das lutas imediatas por direitos sociais e trabalhistas, bem como sua perspectiva histórica de luta anticapitalista no horizonte de uma sociedade emancipada de auto-organização dos indivíduos livremente associados, na perspectiva marxiana.

\section{NOTAS}

1. Padrão produtivo do capitalismo caracterizado pela flexibilidade nos processos de trabalho, mercados, produtos e padrões de consumo.

2. Fordismo-taylorismo - padrão produtivo do capitalismo desenvolvido no século passado, que tem como características: produção em massa, produção concentrada e verticalizada, com controle de tempo e movimentos

3. É a denominação estabelecida ao conjunto de medidas e políticas necessárias à implementação do projeto neoliberal no continente Lati- 
no-americano, que tiveram o consenso do Fundo Monetário Internacional (FMI), do Banco Interamericano de Desenvolvimento (Bird), do Banco Mundial e do governo norte-americano, em reunião ocorrida em Washington, em 1989.

4. Redimensionamento do papel do Estado, atribuindo-lhe como missão precípua a segurança, a fiscalização e a arrecadação. Ênfase à transferência para a iniciativa privada de caráter público das políticas sociais.

\section{REFERÊNCIAS BIBLIOGRÁFICAS}

ABRAMIDES, M.B.; CABRAL, M.S.R. O novo sindicalismo e o serviço social. São Paulo: Cortez, 1995.

ANDERSON, P. Balanço do neoliberalismo. In: SADER, E.; GENTILLE, P. (Org.). Pós-neoliberalismo - as políticas sociais e o estado democrático. Rio de Janeiro: s. ed., 1995.

ANTUNES, R. Lutas sociais e desenho societal no Brasil dos anos 90. Revista Crítica Marxista. São Paulo: Xamã VM, n.7, 1998.

. Adeus ao trabalho? Ensaio sobre as metamorfoses e a centralidade do mundo do trabalho. São Paulo: Cortez, 1995.

DIAS, E.C. Saúde do trabalhador. Saúde, Meio Ambiente e Condições de Trabalho - conteúdos básicos para uma ação sindical. São Paulo: Publicação CUT/Fundacentro, 1995.

HARVEY, D. A condição pós-moderna. São Paulo: Loyola, 1995.

LAURELl, A.C.; NORIEGA, M. (Org.). Processo de reprodução e saúde - Trabalho e desgaste operário. São Paulo: Hucitec, 1989.
MAtTOS, U.A.O.; PORTO, M.F.S.; FREITAS, N.B.B. Novas tecnologias, organização do trabalho e seus impactos na saúde, no meio ambiente. Saúde, Meio Ambiente e Condições de Trabalho - conteúdos básicos para uma ação sindical. São Paulo: $\mathrm{Pu}$ blicação CUT/Fundacentro, 1995.

MOTTA, A.E. Cultura da crise da seguridade social - Um estudo sobre as tendências da previdência social e da assistência social nos anos 80 e 90. São Paulo: Cortez, 1995.

NETTO, J.P. Crise do socialismo e ofensiva neoliberal. São Paulo: Cortez, 1994.

RIBEIRO, H.P. A violência do trabalho no capitalismo - o caso dos membros superiores pelo esforço repetitivo em trabalhadores bancários. 1997. Tese (Doutorado) - USP, São Paulo, 1997.

A violência oculta do trabalho - As lesões por esforço repetitivo. Rio de Janeiro: Fiocruz, 1999.

VIERA, E. O Estado e a sociedade civil perante o ECA e a LOAS. Revista Serviço Social e Sociedade. São Paulo: Cortez, ano XIX, n.56, mar. 1998 .

Maria Beatriz Costa Abramides: Professora da Faculdade de Serviço Social e Coordenadora do Núcleo Temático "Relações de Trabalho" da PUC-SP.

Maria do Socorro Reis Cabral: Professora da Faculdade de Serviço Social e Coordenadora do Núcleo Temático "Qualidade de Vida e Saúde" da PUC-SP. 